\title{
Lithium Toxicity
}

Sophie Corriveau MD, Amanda Gardhouse MD, Mark Soth MD, Craig Ainsworth MD

\section{About the Authors}

Sophie Corriveau (right) is a 3rd-year internal medicine resident, Amanda Gardhouse is a 3rd-year internal medicine resident, Mark Soth is an associate professor in critical care, and Craig Ainsworth is a clinical scholar in cardiology/critical care, all with McMaster University, in Hamilton, Ontario. Correspondence may be directed to sophie.corriveau@medportal.ca.

\section{Summary}

Lithium is commonly prescribed for mood stabilization in bipolar disorder. Lithium has a narrow therapeutic range $(0.8-1.2 \mathrm{mmol} / \mathrm{L})$, and even chronic users may unexpectedly develop toxic levels. Toxicities manifest in various ways. The authors report the case of a patient who developed sinus bradycardia and asystolic arrest with an elevated serum lithium level.

\section{Résumé}

Le lithium est couramment prescrit dans le traitement du trouble bipolaire pour son effet de psychorégulation. La marge thérapeutique du médicament est étroite ( 0,8 à $1,2 \mathrm{mmol} / \mathrm{l})$, et sa concentration peut atteindre le seuil toxique même chez l'utilisateur de longue date. Les manifestations de la toxicité du médicament prennent diverses formes. Les auteurs présentent un cas d'élévation du taux sérique de lithium et d'arrêt cardiaque asystolique par suite de bradycardie sinusale.

Lithium continues to be the primary agent used in bipolar disorder. ${ }^{1,2}$ More than $80 \%$ of patients taking lithium experience adverse effects including cardiotoxicity. ${ }^{1,2}$ Cardiac toxicities are described in the literature and include $\mathrm{T}$-wave flattening, sinus node dysfunction, prolonged Q-T interval, atrioventricular blockade, and ventricular arrhythmias. ${ }^{3-7}$ Rarely described are cardiac arrests, with successful resuscitation. In the case presented below, our patient required cardiopulmonary resuscitation and temporary transvenous pacing, and had eventual resolution of sinus node dysfunction with cessation of the offending agent, lithium.

\section{Case}

A 54-year-old woman with a past medical history of bipolar disorder, dyslipidemia, and reflux disease presented to a peripheral hospital with bizarre behaviour and an altered level of consciousness. Vital signs were stable at presentation (heart rate 67 beats per minute [bpm], blood pressure 164/86 mm Hg, temperature $36.7^{\circ} \mathrm{C}$ ) and she was triaged as a level 2 (low priority). On questioning, the patient's family reported increased confusion and decreased oral intake for the preceding
48 hours, although the patient had continued to take all medications as prescribed. Preadmission medications included lithium $300 \mathrm{mg}$ twice daily, lorazepam $1 \mathrm{mg}$ at night, trazodone $100 \mathrm{mg} / \mathrm{d}$, sertraline $150 \mathrm{mg} / \mathrm{d}$, rosuvastatin calcium (Crestor) $20 \mathrm{mg} / \mathrm{d}$, and omeprazole $20 \mathrm{mg}$ daily.

While waiting in the emergency department, the patient had a witnessed generalized tonic-clonic seizure requiring intubation. While intubated, she became bradycardic and had an asystolic arrest for which a "code-blue" was called; resuscitation efforts were initiated for a total of 5 minutes. Once stabilized, she was transferred to a tertiary-level intensive care unit.

On arrival to the tertiary care centre, the patient was hypotensive at $60 / 40 \mathrm{~mm} \mathrm{Hg}$ on vasopressor support, and her heart rate was $40-50 \mathrm{bpm}$ with bigeminy. The patient was sedated and ventilated on pressure control of $18 / 8$ with an $\mathrm{FIO}_{2}$ of $100 \%$ with normal oxygen saturation. Physical examination was significant for increased tone and reflexes symmetrically in lower extremities, but was otherwise non-contributory.

Lithium level was elevated at $2.82 \mathrm{mmol} / \mathrm{L}$ (normal range is $0.5-1.2 \mathrm{mmol} / \mathrm{L}$ ). Other laboratory values revealed normal 


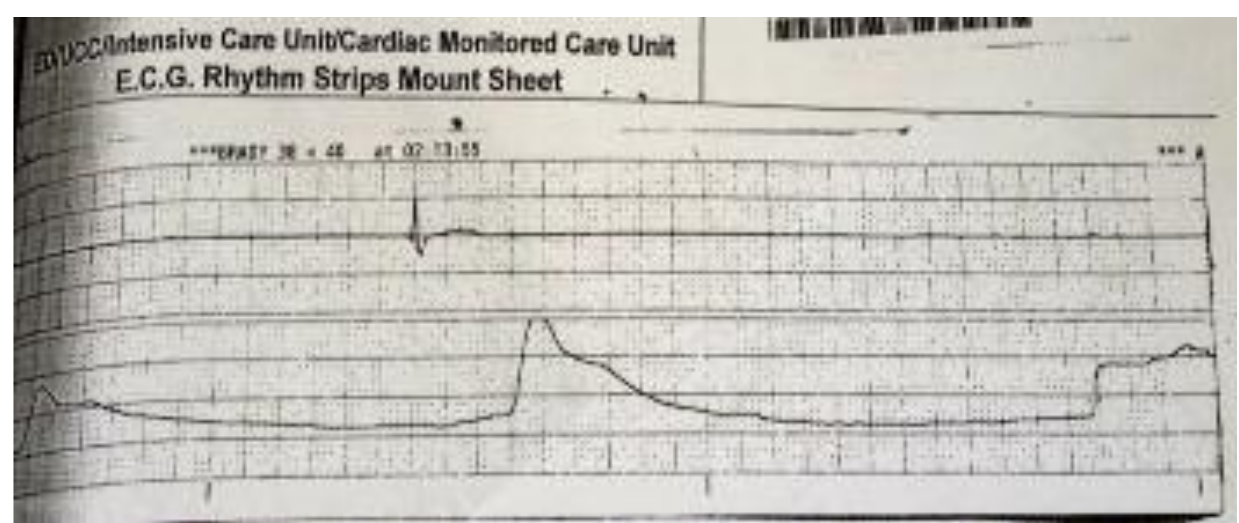

Figure 1. Pre-arrest electrocardiogram.

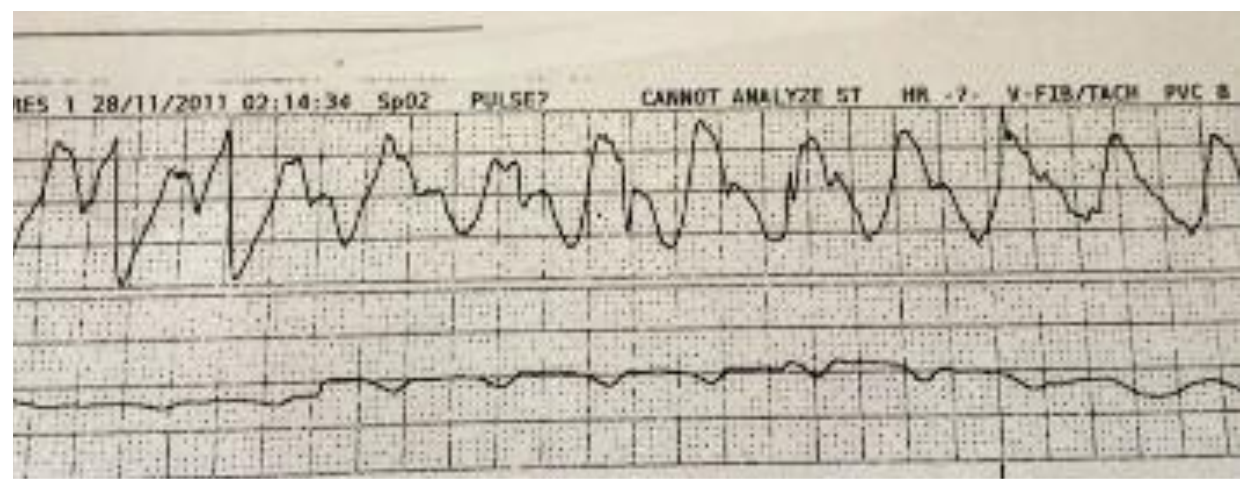

Figure 2. Electrocardiogram during arrest.

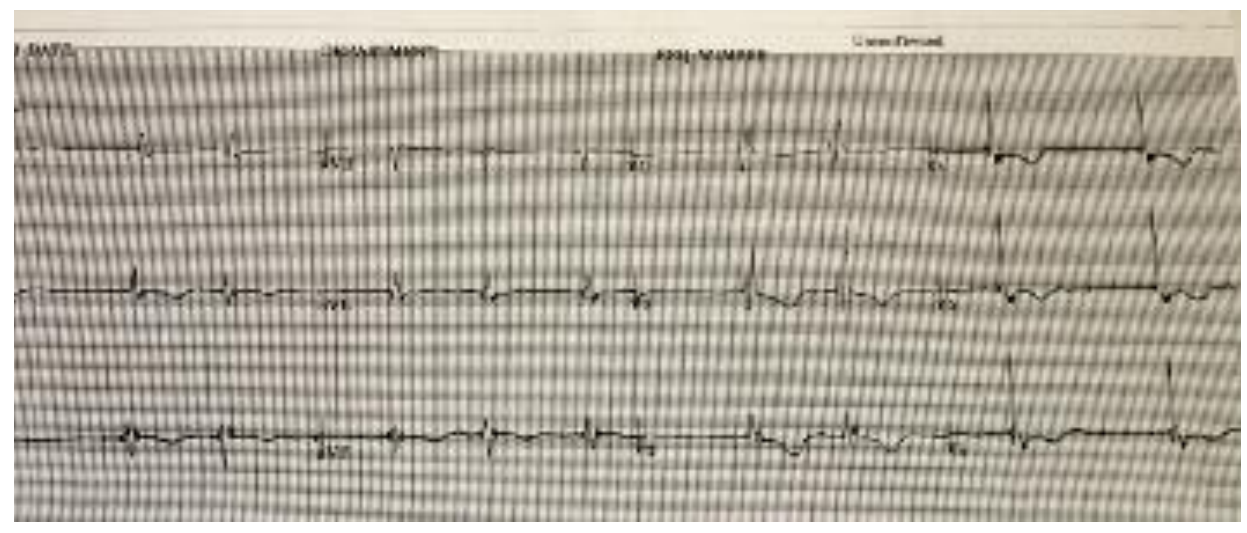

Figure 3. Post-arrest electrocardiogram.

electrolytes and extended electrolytes, elevated creatinine at $138 \mu \mathrm{mol} / \mathrm{L}$ (baseline $80 \mu \mathrm{mol} / \mathrm{L}$ ), a lactate level of $3.4 \mathrm{mmol} / \mathrm{L}$, an international normalized ratio of (INR) 2.0, venous blood gas (VBG) 7.26/36/30/16 with $\mathrm{Svo}_{2} \mathrm{0.50}$, a troponin T level of 0.18 then $0.05 \mu \mathrm{g} / \mathrm{L}$, and a thyroid stimulating hormone (TSH) level of $2.2 \mathrm{mU} / \mathrm{L}$. A computed tomographic scan of the head, completed at the peripheral site, was unremarkable. An electrocardiogram revealed bradycardia, with heart rates between 35 and $60 \mathrm{bpm}$ with junctional rhythm (Figures 1 and 2).

Due to ongoing bradycardia, the patient required trans- venous pacing for 48 hours, at which time the lithium level was $<0.8 \mathrm{mmol} / \mathrm{L}$; her underlying rhythm returned (Figure 3).

\section{Discussion}

Lithium is a monovalent cation like sodium and potassium. ${ }^{1}$ At the cellular level, lithium competes with these cations and displaces them, leading to intracellular metabolic changes. ${ }^{1,2}$ Lithium is excreted almost completely by the kidneys and handled in the same manner as sodium, being freely filtered with $80 \%$ reabsorption at the proximal tubules. ${ }^{1,2}$ Sodium intake and lithium clearance are directly related, and decreasing sodium intake may lead to decreased clearance of lithium. ${ }^{1}$ For this reason, lithium intoxication is more commonly encountered in low-salt diets, states of dehydration, or with a concurrent use of diuretics. ${ }^{1,2}$ Prior to her presentation, our patient had been feeling unwell, with decreased oral intake, but continued to take her lithium as prescribed. This led to lithium accumulation given her state of acute kidney injury. This situation is common to many patients taking lithium and exemplifies the importance of educating our patients to seek medical advice and hold their lithium in states of dehydration and decreased oral intake to prevent toxic accumulation. Patients on steady dosages of lithium should have their levels monitored every 6 months along with a urinalysis, serum creatinine level, blood urea nitrogen (BUN) level, and thyroid function test. ${ }^{1,8}$ Monitoring should occur more frequently with the initiation of treatment and when any adjustments in lithium dosage are made. ${ }^{8}$

The mechanism by which lithium exerts toxic effects on the cardiac system is not fully understood. The monovalent nature of lithium and the cations involved in cardiac electrophysiology are likely integral to understanding these toxicities. Sodium and potassium channels and cation fluxes are required for depolarization, cardiac contraction, and repolarization within the cardiac cycle. Lithium has been shown to block cardiac sodium channels at non-toxic levels. ${ }^{3}$ Lithium has also been postulated to affect cardiac potassium channels, thereby affecting the resting 
membrane potential by its ability to partially replace intracellular potassium. ${ }^{4,5}$ Another mechanism by which lithium can affect the cardiac system is by its effects on the thyroid, which have been well documented; however, in the case reports reviewed, this was not the case. ${ }^{6}$

Although cardiac abnormalities are infrequent, the most common lithium-induced toxicity is T-wave flattening or inversion, which is usually an incidental finding that reverses with discontinuation of the drug. ${ }^{5}$ In a retrospective observational study of lithium exposure, the incidence of cardiac complications was examined and reported in $6 \%$ of all hospitalized lithium overdose cases. ${ }^{3,7}$ Most commonly reported was sinus bradycardia without hypotension, followed by sinus bradycardia with hypotension, third-degree atrioventricular (AV) block, sinus node arrest, and bradycardic cardiac arrest. ${ }^{7}$ All of the cases of bradycardia with hypotension, AV block, sinus node arrest, and bradycardic arrest occurred in patients with chronic exposure to lithium., ${ }^{3,8}$ There are also case reports of Brugada-pattern electrocardiographic changes induced by lithium. ${ }^{910}$ Interestingly, sinus node dysfunction has also been reported at therapeutic serum levels of lithium. ${ }^{11,12}$

This case report reiterates that lithium can have devastating consequences on the cardiac cycle. Specific to our patient, toxic serum lithium levels were associated with sinus bradycardia, hypotension, and sinus node dysfunction, leading to arrest.

\section{References}

1. Gray J, ed. e-Therapeutics. Ottawa (ON): Canadian Pharmacists Association, 2007; http://www.etherapeutics.ca.normedproxy.lakeheadu.ca. Accessed May 12, 2012.

2. Sadock B J, Sadock VA. 2007. Synopsis of Psychiatry, 10th edition. Philadelphia (PA): Lippincott Williams and Wilkins; 2007.

3. Bailey B, McGuigan M. Lithium poisoning from a poison control centre perspective. Ther Drug Monit 2000;22(6):650-5.

4. Tilkian A, Schroeder J, Kao J, Hultgren H. The cardiovascular effects of lithium in man. Am J Med 1976;61:665-70.

5. Brady H, Horgan J. Lithium and the heart: unanswered questions. Chest 1988;93:166-9.

6. Livingstone $\mathrm{C}$, Rampes $\mathrm{H}$. Lithium: a review of its metabolic adverse effects. J Psychopharmacol 2006;20(3):347-55.

7. Offerman S, Alsop J, Lee J, Holmes J. Hospitalized lithium overdose cases reported to the California Poison Control System. Clin Toxicol 2010;48:443-8.

8. Wright D, Salehian O. Brugada-type electrocardiographic changes induced by long-term lithium use. Circulation 2010;122:418-9.

9. Singh L, Praharaj K, Munda S, Khess C. Lithium-induced sinus node dysfunction at therapeutic serum levels. Nat Med J India 2011;24(3):151-2.

10. Talati S, Aslam A, Vasavada B. Sinus node dysfunction in association with chronic lithium therapy: a case report and review of literature. Am J Therapeut 2009;16(3):274-8.

11. Jefferson J. A clinican's guide to monitoring kidney function in lithium treated patients. J Clin Psychiatr 2010;71(9):1153-7.

12. Darbar D, Yang T, Churchwell K, et al. Unmasking of Brugada syndrome by lithium. Circulation 2005;112:1527-31. 